\title{
Improving the Predictability of Severe Convective Weather Processes by Using Wind Vectors and Potential Temperature Changes: A Case Study of a Severe Thunderstorm
}

\author{
Hao Wang, ${ }^{1}$ Gangyi Chen, ${ }^{2}$ Huanhuan Lei, ${ }^{3}$ Yongqian Wang, ${ }^{4}$ and Shunxian Tang ${ }^{1}$ \\ ${ }^{1}$ College of Meteorological Observation, Chengdu University of Information Technology, Chengdu 610225, China \\ ${ }^{2}$ College of Management, Chengdu University of Information Technology, Chengdu 610225, China \\ ${ }^{3}$ Key Laboratory of Meteorological Disasters, Ministry of Education, Nanjing University of Information Science \& Technology, \\ Nanjing 210044, China \\ ${ }^{4}$ College of Resources and Environment, Chengdu University of Information Technology, Chengdu 610225, China
}

Correspondence should be addressed to Hao Wang; wh@cuit.edu.cn

Received 4 April 2016; Revised 14 June 2016; Accepted 20 June 2016

Academic Editor: Eduardo García-Ortega

Copyright (c) 2016 Hao Wang et al. This is an open access article distributed under the Creative Commons Attribution License, which permits unrestricted use, distribution, and reproduction in any medium, provided the original work is properly cited.

\begin{abstract}
Strong, local convective weather events are capable of causing extensive damage, but weather observation systems with limited resolution and radar monitoring can typically provide only a few minutes to hours of prior warning time. This paper presents a comprehensive case study of the cumulative evolution of several characteristic quantities during one extremely severe convective weather process. The research results indicate that the main feature of strong convective weather is the uneven distribution of thermal energy in the atmosphere, and the structure of this heat distribution determines the level of instability in the atmosphere. A vertical "clockwise rolling current" occurs in the wind field structure at the beginning of the process, and this is accompanied by a rapid drop in temperature at the top of the troposphere. When these signs occurred in the case study, radar technology was used to refine the precipitation region and spatial characteristics of the approaching storm. The height and vertical evolution of radar echoes were indicative of the characteristics of the system's movement through space. Such findings may be useful for improving the forecasting times for strong convective weather.
\end{abstract}

\section{Introduction}

Severe convective weather events refer to sudden, severe, very destructive weather phenomena that often include thunderstorms, hail, tornadoes, and locally heavy rain. Severe convective weather events occur in mesoscale weather systems, and they are small in size ranging from about tens of kilometers to two or three hundred kilometers in diameter on average; some are actually as small as tens of meters to tens of kilometers across. These small events occur very suddenly and are especially short lived [1]. Precipitation during the course of severe convective weather events can be intense, and the duration of heavy or torrential rain can last for a few hours to tens of hours. Such localized heavy rains can destroy agricultural crops and damage industrial and transportation infrastructure, and any associated flooding or landslide hazards may even endanger people's lives. Thus, early warning systems for severe convective weather events are urgently needed.

Currently, weather analysis is mainly diagnostic in nature, and weather predictions are mostly made on the basis of linear extrapolations and numerical prediction models. While these can be effective tools on a synoptic scale, they cannot accurately predict sudden, small-scale, local weather events. They might not even be able to predict such local weather at all. A few reasons for this are as follows. (1) These weather processes are small and very sudden, and current observation systems do not have adequate temporal or spatial resolutions to model them effectively. Radar observations are generally limited to a few hours or minutes of early warning times. (2) Air pressure analysis data can display hysteresis [2]. The root causes of severe convective weather are the changes in and the uneven distribution of thermal energy in the atmosphere. 
Thermal energy changes inevitably cause atmospheric density changes and restructuring. Thus, air pressure changes are created, and there is a sequential relationship between the thermal energy and the air pressure. Since initial conditions preceding sudden events can vary, it is difficult to use extrapolation methods to predict them. However, before sudden changes occur in any weather system, an energy accumulation process develops with corresponding changes in the dynamic conditions, thermal conditions, and water vapor conditions. These changes will alter the internal structure of the system and eventually lead to severe local weather processes. How to use this information to accurately predict these types of processes is an urgent question in meteorological research.

Much research has been done on severe, local, convective weather. Most research to date has adopted one of the following formats: (1) index research or (2) mechanistic research. In index research, researchers combine heat and humidity characteristics in the lower and middle troposphere with wind shear changes to design several indices for atmospheric energy changes [3-7]. On this basis, the indices are modified $[8,9]$ to estimate the likelihood that convection and severe weather could develop in the atmosphere. Thus, the indices mentioned above are mostly used as singlevalued indices to evaluate the state of the atmosphere. As such, the overall dynamic, heat, and water vapor conditions are not clear. This makes them less accurate as early warning and forecasting tools for severe convective weather. In mechanistic research, the structural and developmental mechanisms of medium- and small-scale severe convective weather systems are studied, which has proven to be difficult. More research on the mechanisms by which such systems are triggered and strengthened is especially needed. The mechanisms are closely related to atmospheric dynamics. Low-level convergence, orographic lift, and gravity waves are all important triggering mechanisms for convective motion [10-12]. In terms of unstable energy, Wang et al. [13] studied how precipitation and changing thermal conditions corresponded to surface temperatures in basins. However, the characteristics of dynamic and thermal changes vary by season and by region. Thus, it is difficult to come up with a single standard that would cover the special characteristics of severe convective weather [14].

In summary, the occurrence of strong convective weather is closely related to an unstable energy distribution (thermal conditions), the water vapor saturation level (water vapor conditions), and some triggering lift mechanism (dynamic conditions). The combination of these three factors causes weather processes to evolve. In 1998, Ouyang [2] proposed that the characteristics of wind vector and potential temperature changes could be used for studying the overall status of atmospheric thermal, dynamic, and water vapor conditions. Ouyang also summarized the typical features displayed by these three factors before the occurrence of meteorological events. On the basis of this research, several researchers have carried out numerous studies that focused on catastrophic weather, for example, hail, local heavy rainfall, thunderstorms, dust storms, abnormally high temperatures, and low visibility weather [15-19]. This approach has a high predictive capacity for the sudden evolution of weather events, and it can greatly improve the accuracy of predictions for catastrophic weather. A product based on this method has become one of the key prediction products included in the new generation Chinese Meteorological Information Comprehensive Analysis and Processing System (MICAPS) program hosted at various Chinese meteorological departments. However, this method is not "fully quantitative," which would be ideal, and it produces a mixture of qualitative and quantitative information. Specifically, the method employs various tools such as information systems, methodological systems, and monitoring and computational techniques. There is still room for improvement in regard to this method. Alternatively, Doppler weather radar can track the changing process of weather events and provide information on the strength and speed of targets, and it has been widely used in forecasting operations [20]. The present study aims to combine the advantages of these two methods. Wind vector and potential temperature changes were used for qualitative studies of strong convective weather processes. Radar information was used for more accurate quantitative assessments of local weather events. The ultimate goal was to improve the accuracy of predictions for strong convective weather.

Section 2 introduces the data and methods used in this study, and Section 3 presents the results and discussion material. Section 3 is divided into two subsections, where the first one focuses on the characteristic changes in the convection system processes and the second one focuses on the use of radar information to closely examine the characteristics of an individual severe convective weather process. The conclusions are presented in Section 4.

\section{Data and Methods}

This research utilized conventional radiosonde data on the vertical structure of the atmosphere; the temporal resolution of the data was twice daily (LT 08:00 a.m. and 08:00 p.m.), and levels ranged from the surface to $100 \mathrm{hPa}$. The types of data collected included wind directions, wind speeds, temperatures, humidity values, and pressures at two individual stations. Compared with the data obtained from using current and widely applied continuity and smoothness processing methods (interpolation, fitting, extrapolation, etc.), the data used in this method were real but not continuous. Data integrity was thus better maintained, as information obtained after data processing may be damaged. Relatively severe damage can lead to misjudgments of the vortex structure and cause failures in the predictions [2]. The data used in this study provided an intuitive display of changes in the unstable energy structure of the atmosphere and reflected the unevenness of the structure well. A typical " $V-3 \theta$ " plot analysis of the radiosonde data was employed, where " $V$ " represents the horizontal wind vectors at each altitude and " $3 \theta$ " represents the three different potential temperatures, namely, the potential temperature $\theta$, the pseudoequivalent potential temperature $\theta_{\text {sed }}$, and the pseudoequivalent potential temperature assuming a saturated state $\theta^{*}$. The potential temperature expresses the vertical distribution of thermal energy in the atmosphere. In regard to $\theta_{\text {sed }}$, the traditional way of calculating 
the pseudoequivalent potential temperature from the temperature at the condensation height was abandoned, and instead we calculated the new potential temperature from the dew point temperature. The significance of this is that condensation is approaching precipitation and analysis of the atmospheric humidity content before condensation gives more pertinent information. $\theta^{*}$ is the potential temperature assuming a saturated state at the current temperature; it provides a reference for comparisons to help grasp the distribution of water vapor in the atmosphere. The specific definitions and calculations used in this study are as follows [21].

(1) Calculation of the Potential Temperature $\theta$. Potential temperature is the temperature that a parcel of air would have if it were dry-adiabatically expanded or compressed to the standard atmospheric pressure. The potential temperature of unsaturated, moist air is defined as follows:

$$
\theta=T\left(\frac{P_{0}}{P}\right)^{R / C_{p}} .
$$

In this formula, $\theta$ is the potential temperature, $T$ is the kelvin temperature $(\mathrm{K}), P_{0}$ is sea level pressure $(\mathrm{hPa}), P$ is the pressure (hPa), $R$ is the gas constant of air, and $C_{p}$ is the specific heat capacity at a constant pressure. For unsaturated, moist air, $R / C_{p}$ can be calculated as $R / C_{p}=$ $\left(R_{d} / C_{p d}\right)((1+0.608 q) /(1+0.86 q))$, where $R_{d} / C_{p d}$ is the corresponding $R / C_{p}$ value for a dry parcel of air. Specific humidity $q$ in the atmosphere is always less than 0.04 , so $0.99<\left(R / C_{p}\right) /\left(R_{d} / C_{p d}\right)<1$, and thus $R / C_{p} \approx R_{d} / C_{p d}=$ 0.2854 .

(2) Calculation of the Pseudoequivalent Potential Temperature $\theta_{\text {sed }}$. Pseudoequivalent potential temperature $\theta_{\text {sed }}$ is defined as follows. If a parcel of air adiabatically rises until all of the moisture condenses, the largest $\theta$ value it achieves is the pseudoequivalent potential temperature. The imaginary adiabatic process is separated into two parts. The dry adiabatic process comes first; it lasts until the parcel is saturated. During this process, potential temperature is conserved. In the second part, as water vapor condenses, potential temperature increases according to

$$
\theta_{\text {sed }}=\theta_{d} \exp \left(\frac{L_{w} r}{C_{p d} T_{c}}\right)
$$

In this formula, $\theta_{d}$ represents the potential temperature of moist air contained in dry air, where

$$
\theta_{d}=T\left(\frac{P_{0}}{P-e_{s}}\right)^{R_{d} / C_{p d}}
$$

Here, $e_{s}$ is the saturation vapor pressure at centigrade temperature $t$ in $\mathrm{hPa}$; the formula is as follows:

$$
e_{s}=6.112 \exp \left(\frac{17.67 t}{t+243.5}\right)
$$

In formula (2), $T_{c}$ is the temperature at the lifting condensation level, and the latent heat of vaporization $L_{w}=$ $(2.501-0.00237 t) \times 10^{6} \mathrm{~J} \cdot \mathrm{kg}^{-1}$, which increases slightly as the temperature decreases. $r$ is the mixing ratio, and $r=$ $0.622\left(e_{s} /\left(P-e_{s}\right)\right) \mathrm{g} \cdot \mathrm{g}^{-1}$. To calculate $\theta_{\text {sed }}$, the dew point temperature $T_{d}$ is used instead of $T_{c}$ because water vapor condensation is already close to precipitating. Therefore, the analysis of the atmospheric humidity before condensation is more relevant to forecasting.

(3) Calculation of $\theta^{*} \cdot \theta^{*}$ is the calculated value of the pseudoequivalent potential temperature assuming that the air is saturated. This calculation is useful when comparing water vapor conditions in the atmosphere.

The core concept in designing an atmospheric wind vector and potential temperature plot is to consider the structural characteristics of irregular information (here, irregular information is that versus general information). General information refers to data for the following parameters that are applied in the following order: (1) pressure, (2) temperature, (3) humidity, and (4) wind field. These data are used for short-term weather forecasting and analyses. However, the method employed by this study uses data on these parameters in the following order: (1) wind field, (2) humidity, (3) temperature, and (4) pressure. This is opposite to the traditional analysis approach and current research focus. Therefore, it is referred to as irregular information. Unevenness in the structure of the atmosphere is then characterized. Under ideal conditions, potential temperature increases with altitude. If the three $\theta$ curves lean to the left or change very little with increasing altitude, this means that the vertical structure of the troposphere is very unstable. In the middle and low levels of the atmosphere, for $\theta_{\text {sed }}$ and $\theta^{*}$, these conditions are widely present. In conventional methods, this is referred to as moist-adiabatic instability. However, it is rare to see a case where an unstable $\theta$ curve is present in the middle and low levels of the atmosphere; such conditions are commonly encountered in the upper level of the troposphere, particularly in arid and highland areas and in the seasons of winter and spring [22]. Research has shown that, before severe convective weather occurs, if the three $\theta$ curves, especially the $\theta$ curve, suddenly lean to the left or change very little with increasing altitude near $300-100 \mathrm{hPa}$, then an ultra-low temperature phenomenon exists. An ultra-low temperature phenomenon is related to the ionization level of the atmosphere, and its formation and development are also related to water vapor [2]. That is, appropriate quantities of water molecules are ionized by ultra-violet or Röntgen X-ray radiation, thus leading to volumetric expansion and decreases in the temperature [23]. The presence of super-low temperatures promotes the inhomogeneity of the atmospheric thermal structure. In addition, the distance between the three $\theta$ curves can reflect the distribution of dry air, moist air, and saturated air in the atmosphere. As shown in Figure 1, around $600 \mathrm{hPa} \theta_{\text {sed }}$ is close to $\theta^{*}$, and this is indicative of an abundance of moist air in the middle and low levels of the atmosphere. Above $600 \mathrm{hPa}, \theta_{\text {sed }}$ almost superimposes on $\theta^{*}$, and this is 


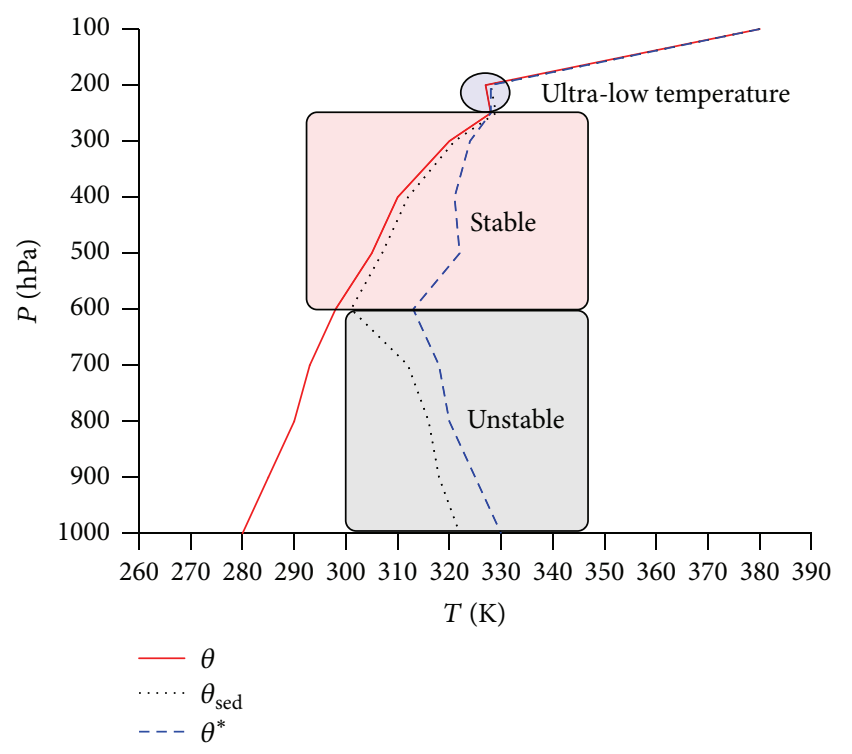

FIgURE 1: $V-3 \theta$ graph. If the angle between the curve and the $x$ axis is approximate to or bigger than $90^{\circ}$, the data indicate that the atmosphere in this area is distributed extremely homogeneously and that this area is a thermally unstable area (gray area). Otherwise, the area is a stable area (pink area). If the unstable area is located between 300 and $100 \mathrm{hPa}$, the phenomenon of ultra-low temperature appears.

indicative of a relative lack of moist air in the middle and low levels of the atmosphere.

Vertical wind shear is at the core of this analysis method. The essence of the high and low pressure zones given by weather maps and numerical predictions is based on the horizontal wind circulation. Horizontal winds are actually the result of rising and falling air movements, not the cause. Therefore, to increase the lead time of weather predictions, the focus should be on changes in vertical motion. The crux of all atmospheric changes is the changing wind direction. The Northern Hemisphere westerlies are a classic example (the easterlies are the opposite). The clockwise "rolling current" (high moisture at low altitude; winds out of the east or south) encourages convection to develop. Warm, moist air rises. The anticlockwise rolling current (low moisture at low altitude; winds out of the west or north) inhibits convection. Dry, cold air sinks. Rolling convection coupled with an unstable heat distribution can cause multiple vertical vortices that constitute a self-circulating system throughout the troposphere $[2,22,23]$. Figure 2 shows the clockwise form of tumbling as the wind in the low and high regions of the atmosphere becomes easterly (southerly) and westerly (northerly), respectively (Figure 2(a)), and when the wind in both the low and high regions of the atmosphere is consistently westerly (northerly) (Figure 2(b)). Figure 3(a) shows the counterclockwise form of tumble. In general, for the Northern Hemisphere, clockwise tumble is caused by easterly (southerly) wind in the low atmosphere and westerly (northerly) wind in the high atmosphere and also by westerly (northerly) wind in both the low and high regions of the atmosphere. In contrast, counterclockwise tumble is caused by easterly (southerly) wind in the high atmosphere and westerly (northerly) wind in the low atmosphere and also by easterly (southerly) wind in both the low and high regions of the atmosphere. The present method is based on the application of thermal wind in actual weather analyses. According to a temperature advection analysis based on wind patterns with altitude at a particular station, if wind is rotating counterclockwise with increasing altitude, this indicates the presence of cold advection, whereas if wind is rotating clockwise with increasing altitude, this indicates the presence of warm advection [24].

\section{Results and Discussion}

3.1. "V-30" Analysis of a Severe Thunderstorm with Hail. On July 27,2007 , at around 8:00 p.m. (local time) in the evening, a rare, severe thunderstorm event occurred in Hubei Province $\left(109-115^{\circ} \mathrm{E}, 27-33^{\circ} \mathrm{N}\right)$. The northwest, southwest, and southeast portions of the region experienced severe thunderstorm conditions. Southern and southwestern Hubei also experienced thunderstorm winds of $18-22 \mathrm{~m} / \mathrm{s}$. Eleven administrative districts in Hubei, including Wuhan $\left(114.31^{\circ} \mathrm{E}\right.$, $\left.30.52^{\circ} \mathrm{N}\right)$, Xianning $\left(114.28^{\circ} \mathrm{E}, 29.87^{\circ} \mathrm{N}\right)$, Jingzhou $\left(112.23^{\circ} \mathrm{E}\right.$, $\left.30.33^{\circ} \mathrm{N}\right)$, and Yichang $\left(111.30^{\circ} \mathrm{E}, 30.70^{\circ} \mathrm{N}\right)$ were affected. By 8:00 p.m. the next day, 374,500 people had been affected, 10 had died, and 323 had suffered injuries. From the $500 \mathrm{hPa}$ atmospheric circulation situation at 8:00 p.m. on July 27 (Figure 4), it was clear that Hubei was situated to the west of a western Pacific subtropical high. Western subtropical areas are zones for the ascension of low-level warm and wet air, and southerly airstreams from western subtropical areas can carry abundant moisture from the sea [24]. This provides adequate external conditions for the occurrence of strong convection weather. The western edge of the subtropical high pressure zone was located near $114^{\circ} \mathrm{E}, 33^{\circ} \mathrm{N}$. Being situated at the western edge of the high pressure zone, the entire Hubei region experienced rather strong winds out of the south and southwest. At the same time, the low pressure system that was developing to the west of the region had started to move into the area. A powerful thunderstorm then developed suddenly, and it affected a large geographical area. While Doppler weather radar could warn of this severe convection event, it could only do so after the strong convection currents had already formed; that is, it could not effectively predict the event.

We now consider the radiosonde data collected from the WUHN $\left(114.30^{\circ} \mathrm{E}, 30.6^{\circ} \mathrm{N}\right)$ and $\mathrm{YICH}\left(111.28^{\circ} \mathrm{E}, 30.7^{\circ} \mathrm{N}\right)$ stations before the storm (Figure 5). Starting at 8:00 a.m. on July 25, 2007, the WUHN station and YICH station $V-3 \theta$ plots show that $\theta_{\text {sed }}$ and $\theta^{*}$ demonstrated quasiparallel zigzag patterns. This is a special characteristic of cumulonimbus convective cloud development [2]. Convective cloud development was more intense at the YICH station. Critically, an "ultra-low temperature" structure appeared at both stations at $250 \mathrm{hPa}$. This exacerbated the temperature gradient (environmental lapse rate) between the ground and the top of the troposphere. The ultra-low temperature phenomenon is a key indicator of severe convective weather. It implies that weather processes are being stimulated and convective cloud systems are moving in the troposphere [23]. Peng et al. [25] 


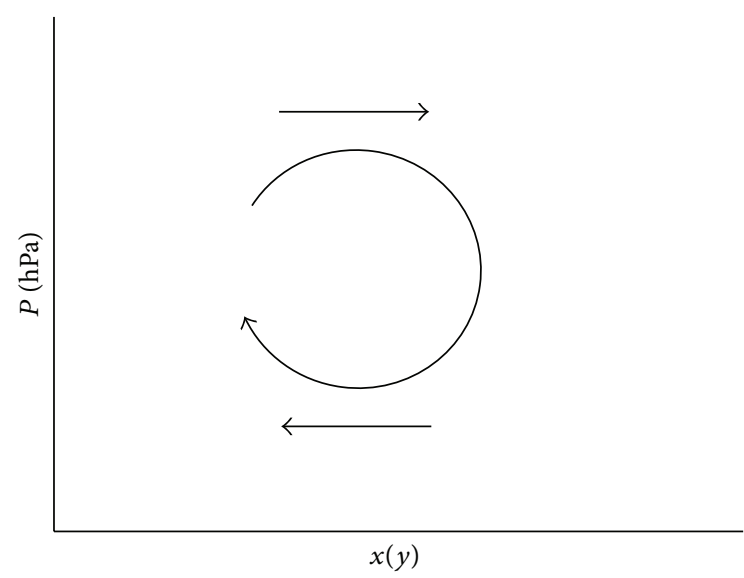

(a)

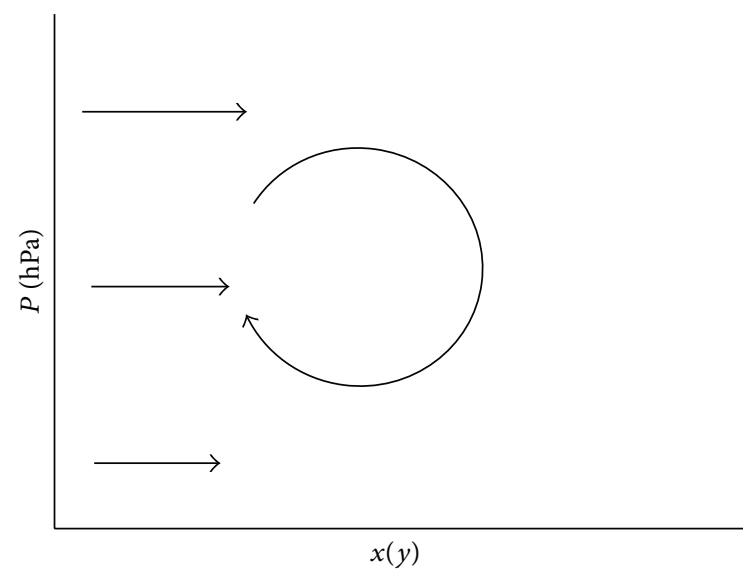

(b)

FIGURE 2: Clockwise form of tumble: (a) easterly (southerly) wind in the low atmosphere and westerly (northerly) wind in the high atmosphere; (b) westerly (northerly) wind in both the low and high regions of the atmosphere.

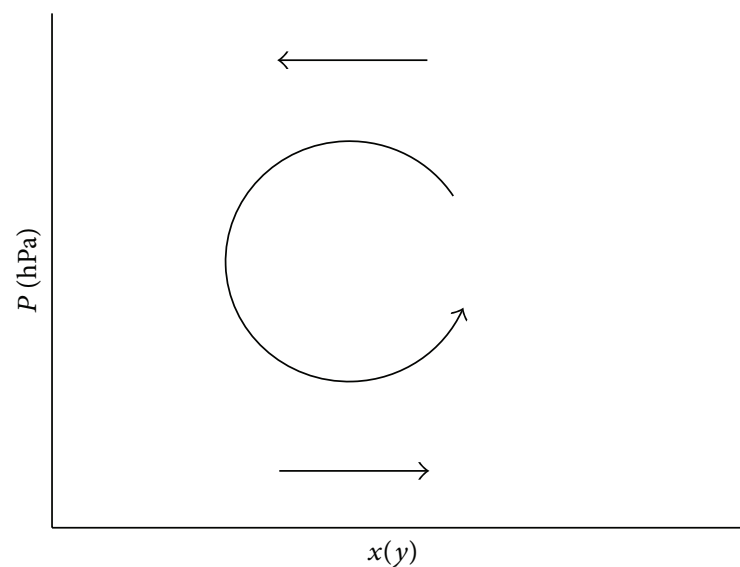

(a)

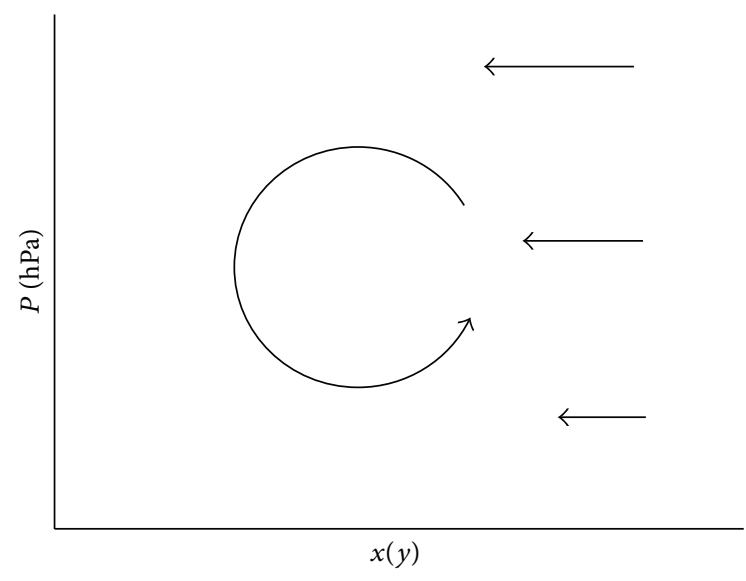

(b)

FIGURE 3: Counterclockwise form of tumble: (a) easterly (southerly) wind in the high atmosphere and westerly (northerly) wind in the low atmosphere; (b) easterly (southerly) wind in both the low and high regions of the atmosphere.

showed that the occurrence of overcast, sunny, windy, and rainy conditions during the evolution of weather can be mainly attributed to atmospheric cooling in the upper troposphere and the influence of solar radiation. If there is no cooling in the upper atmosphere, there will be no clouds and rain in the underlying zone no matter how strong the heating is. Here, it is important to emphasize that the strength of convective activities does not depend on surface temperature alone. The difference in air temperature between the high and low levels of the troposphere is the key element that determines the intensity of convective weather. At 8:00 p.m. on July 25 , the $\theta_{\text {sed }}$ and $\theta^{*}$ curves at both stations inclined to the left at altitudes below $500 \mathrm{hPa}$, thus forming an obtuse angle with the $T$ axis. This is because convective instability in the lower atmosphere, which was caused by the surface heating and water vapor, extended up to $500 \mathrm{hPa}$. That is, there was an overall unstable state at $500 \mathrm{hPa}$ and below. One difference between the two stations was that, at the WUHN station, wind speeds at middle and low altitudes had reached over $10 \mathrm{~m} / \mathrm{s}$. However, at the YICH station, wind speeds were still low. Similarities included the continued existence of ultra-low temperatures near $250 \mathrm{hPa}$ at both stations at this time. This ultra-low temperature phenomenon was more pronounced than it was during the previous sounding, and it manifested itself as larger angles between the three $\theta$ curves and the horizontal at around $250 \mathrm{hPa}$. An overall vertical, clockwise rolling current structure persisted in the troposphere. We note, however, that although southwest water vapor transport at both stations had already reached $500 \mathrm{hPa}$ and above, overall water vapor transport at the YICH station was insufficient. This is indicated by the distance between the $\theta_{\text {sed }}$ and $\theta^{*}$ curves in the plot. This is the essential difference between typical short-time precipitation and continuous precipitation in weather processes [2]. At the YICH station, although it was rather dry at $500 \mathrm{hPa}$ and below, more unstable energy had accumulated than at the WUHN station 


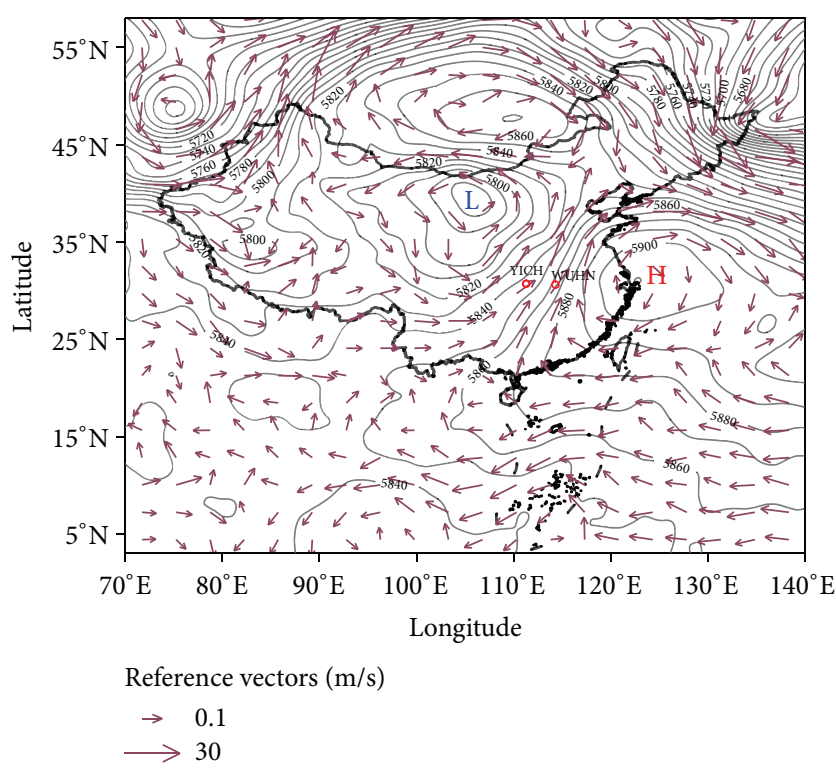

FIgURE 4: Geopotential height and wind field for $500 \mathrm{hPa}$ in East Asia at 20:00 p.m. on July 27, 2007. The hollow red circles show the locations of the YICH and WUHN stations. The data in the figure were derived from the National Centers for Environmental Prediction $(\mathrm{NCEP}) 1^{\circ} \times 1^{\circ}$ reanalysis data.

(the $\theta_{\text {sed }}$ and $\theta^{*}$ trend lines made a larger angle with the horizontal at the YICH station than they did at the WUHN station). Above $500 \mathrm{hPa}$ at the $\mathrm{YICH}$ station, there was abundant water vapor.

By 8:00 p.m. on July 26, 2007, the WUHN station's ultra-low temperature thickness had grown (Figure 6). The angle with the horizontal had reached nearly $90^{\circ}$ in the area stretching to around $200 \mathrm{hPa}$. Thus, this was an extremely unstable phenomenon. At the YICH station, the basic characteristics from the previous sounding remained, but there was more high-level moisture. The above characteristics indicated that severe convective weather would occur at both locations within 6-24 hours [22, 23]. Since unstable energy can be released in the form of precipitation (rain or hail), strong winds, and thunderstorms, according to the particular heat and moisture distributions at each station, the overall moisture insufficiency at the WUHN station meant that the energy would mainly be released in the form of strong winds and local, scattered thunderstorms or hail. At the YICH station, there was abundant water vapor at middle and high altitudes, so the energy would mainly be released in the form of hail and high winds. Here, we must explain that high atmospheric humidity is a predictor of high "quantities" of precipitation. The formation of hail does not require abundant water vapor in the lower zone; mostly there is a relatively wet zone, while other zones remain relatively dry or moisture is distributed more evenly [15]. Combined with the meteorological statistical results for this process, we also found that, at the YICH station, there was a rather high moisture content at middle and high altitudes, so the potential for a large-scale hail event was strong, but at the WUHN station, only localized strong hail could be predicted, and it would be very difficult to predict the quantity. Overall, hail prediction is limited by the spatial distribution of current observation stations and the status of the data, and further research is needed to improve hail quantity and location prediction capabilities. Currently, the locations where hail will fall can only be predicted to be within around $100-150 \mathrm{~km}$ and the quantity is difficult to forecast.

Twelve hours before the storm, ultra-low temperatures and overall clockwise rolling current conditions persisted (Figures 7(a) and 7(c)). At Hubei's YICH station, the water vapor content throughout the troposphere was even higher than it was during the previous measurement period. This latest measurement also shows that hail precipitation and wind intensity at the YICH station were both stronger than they were at the WUHN station. The appearance of the three $\theta$ curves below $500 \mathrm{hPa}$ was already similar to their appearance when the storm began at 8:00 p.m. on July 27, 2007 (Figures 7(b) and 7(d)). However, the key point to note here is that as soon as the ultra-low temperature structure began to weaken, the storm development process accelerated. At the YICH station, the middle and high altitude characteristics changed. Where there used to be abundant moisture at middle and high altitudes, by 8:00 p.m. on July 27 , the conditions were quite dry. This is because the moisture had started to be released in the form of hail. After the end of this severe convective weather process, unreleased, unstable energy could still be found at low and middle altitudes; however, the ultra-low temperature structure weakened and disappeared, and the overall wind pattern was no longer a clockwise rolling structure. This means that the temperature gradient (environmental lapse rate) between the ground and the top of the troposphere had been greatly reduced, and the developmental potential for strong convection weakened and disappeared.

3.2. Analysis of Radar Echoes. Doppler weather radar is widely used in current weather analyses (nowcasting) because it gives real time information about weather processes, including strength and velocity data [20].

On the basis of the qualitative analysis given by the wind vector and potential temperature energy analysis method, Doppler radar can be used to refine the precipitation zone and spatial characteristics to achieve more accurate forecasts and warnings. The Doppler radar (CINRAD/SA, $S$ band) data in this study came from the Hubei Meteorological Administration, WUHN Station. The radar station is located at a longitude of $117.258^{\circ} \mathrm{E}$ and latitude of $31.867^{\circ} \mathrm{N}$, and it is situated at an elevation of $165.51 \mathrm{~m}$ above sea level. Figure 8 shows the base reflectivity from this station at 8:14 p.m., 8:26 p.m., and $8: 38$ p.m. on July 27,2007 . The scanning range was $230 \mathrm{~km}$. The red circles mark the key areas with thunderstorms and strong winds. This figure shows a strong reflection about $20 \mathrm{~km}$ north of the station at 8:14 p.m., and the strength of the reflection was up to $50 \mathrm{dBZ}$. At this time, the severe convection system was developing vigorously. There were reflections from heights of up to $15 \mathrm{~km}$. By 8:26 p.m., the center of the strong convection system had moved to the north and the system had increased in size. However, the size of the severe section in the center had decreased. The strongest 

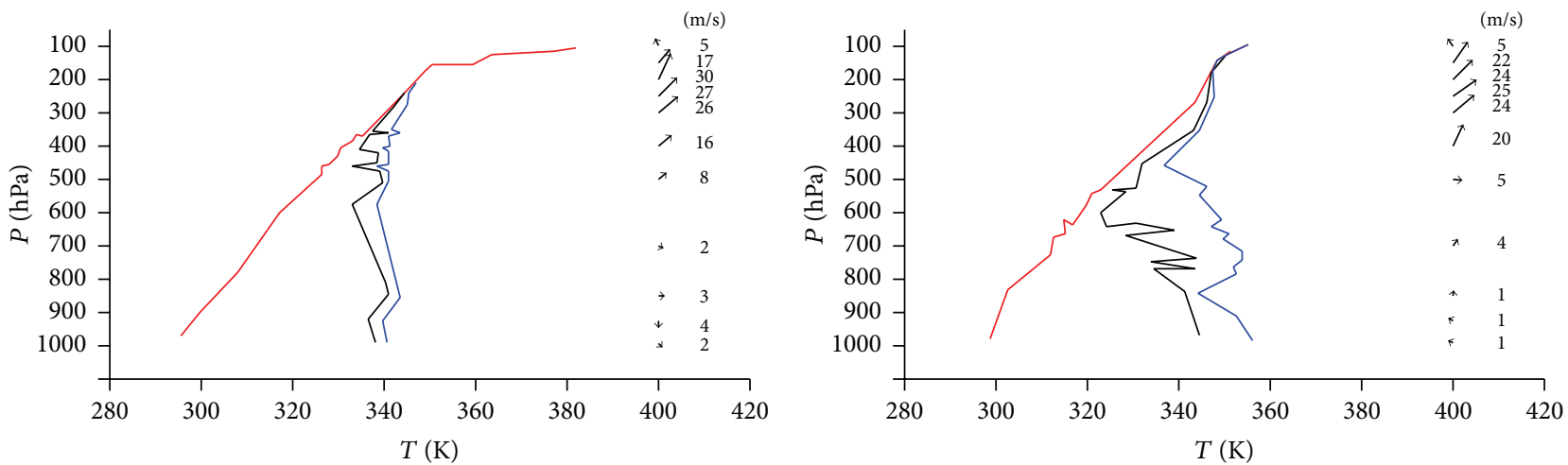

Station: YICH

Station: YICH
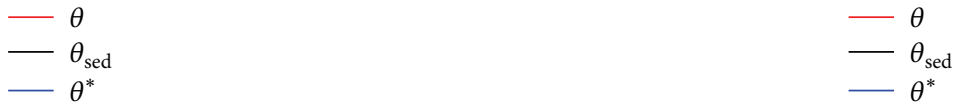

(a)

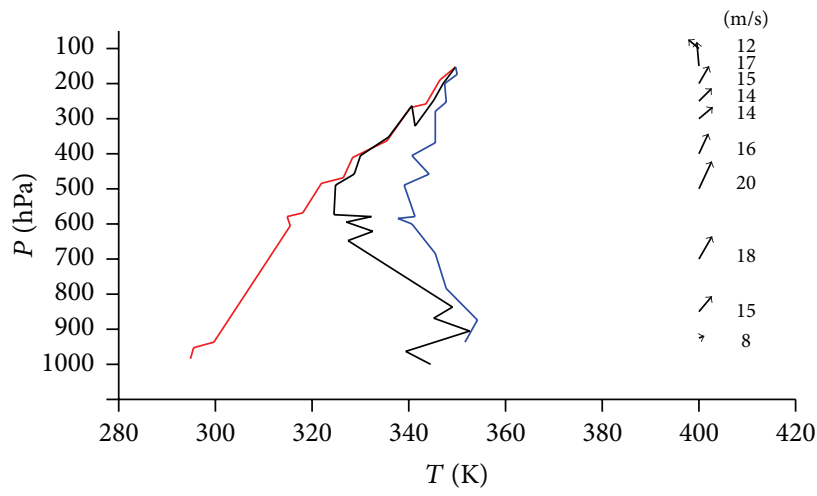

Station: WUHN
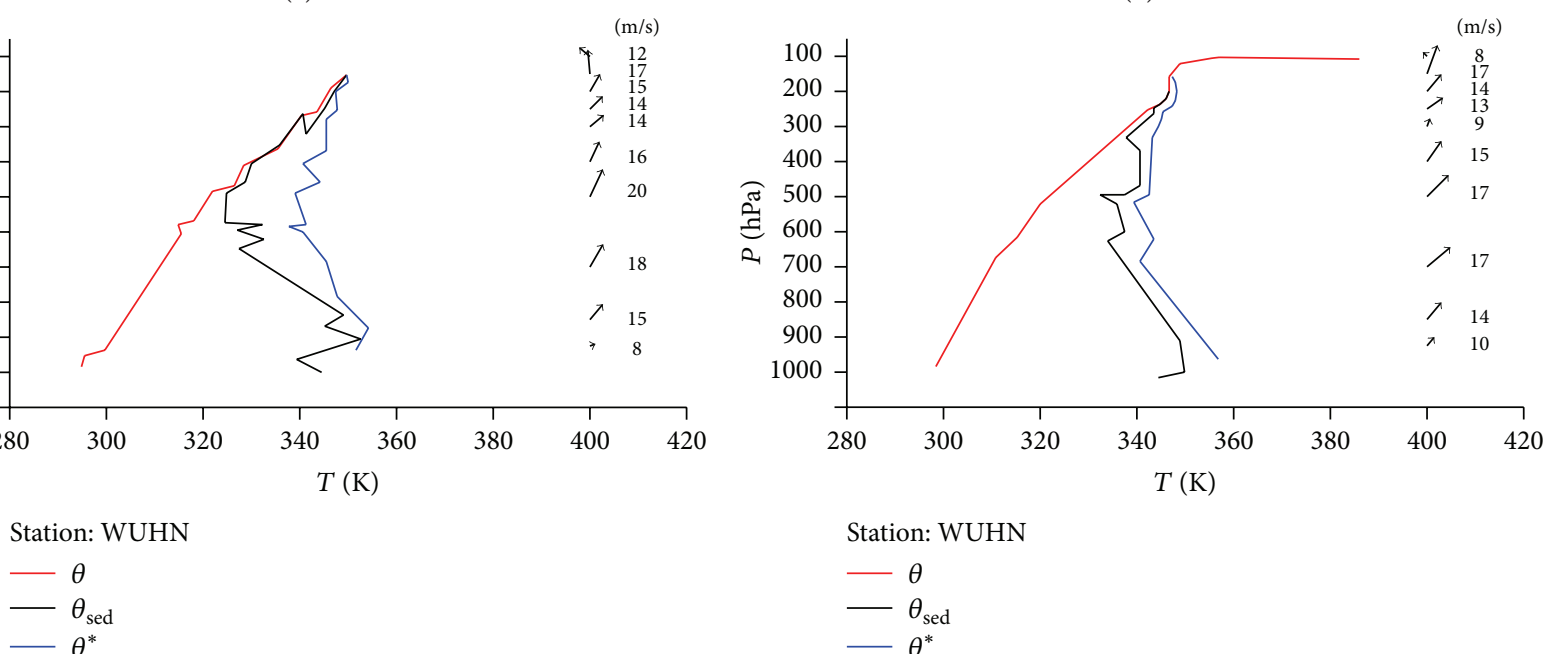

Station: WUHN

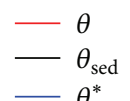

(c)

(d)

Figure 5: $V$-3 $\theta$ distribution conditions: (a) 8:00 a.m. on July 25, 2007, at the YICH station; (b) 8:00 p.m. on July 25, 2007, at the YICH station; (c) 8:00 a.m. on July 25, 2007, at the WUHN station; (d) 8:00 p.m. on July 25, 2007, at the WUHN station. The red lines are the $\theta$ curves, the green lines are the $\theta_{\text {sed }}$ curves, and the blue lines are the $\theta^{*}$ curves.
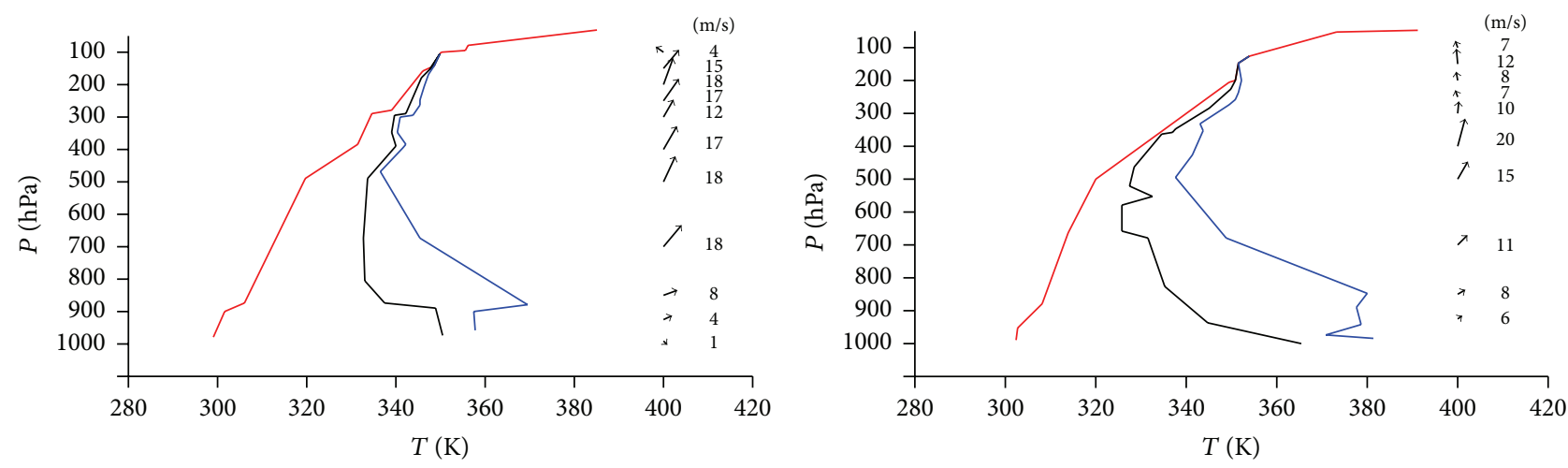

Station: $\mathrm{YICH}$

Station: WUHN
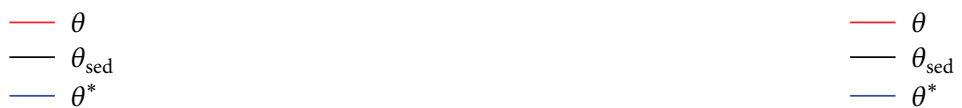

(a)

(b)

FIgURE 6: $V$-3 $\theta$ distribution conditions: (a) 8:00 p.m. on July 26, 2007, at the YICH station; (b) 8:00 p.m. on July 26, 2007, at the WUHN station. The red lines are the $\theta$ curves, the green lines are the $\theta_{\text {sed }}$ curves, and the blue lines are the $\theta^{*}$ curves. 

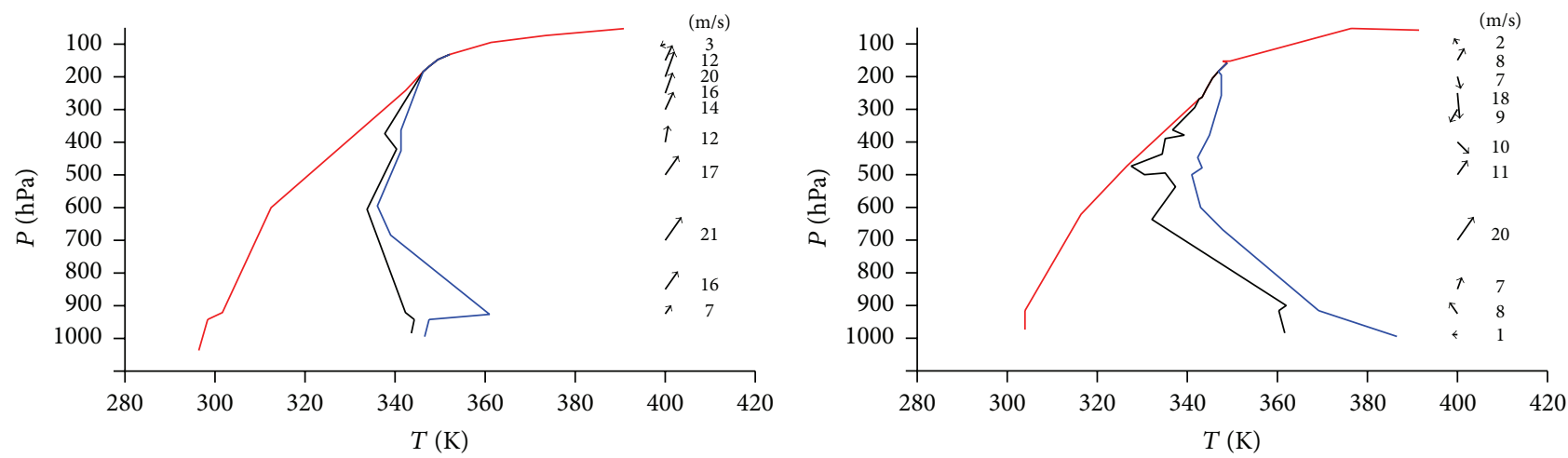

Station: YICH

Station: YICH

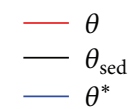

(a)

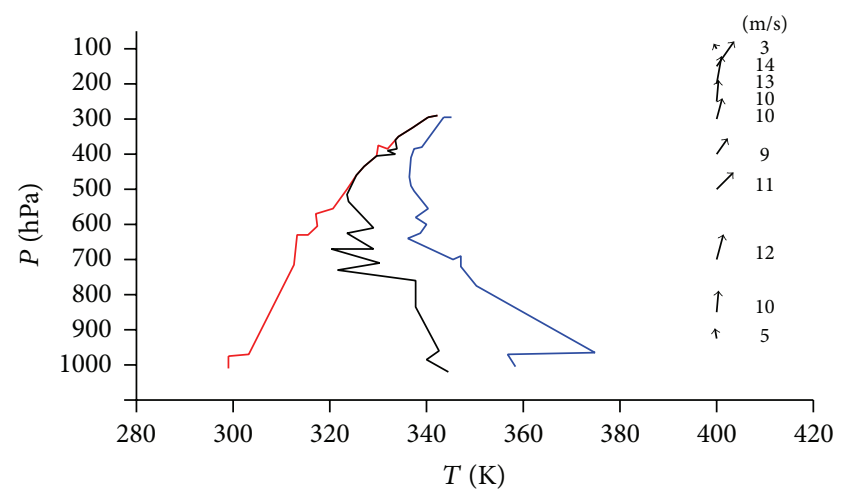

Station: WUHN

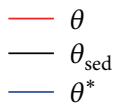

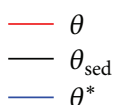

(b)

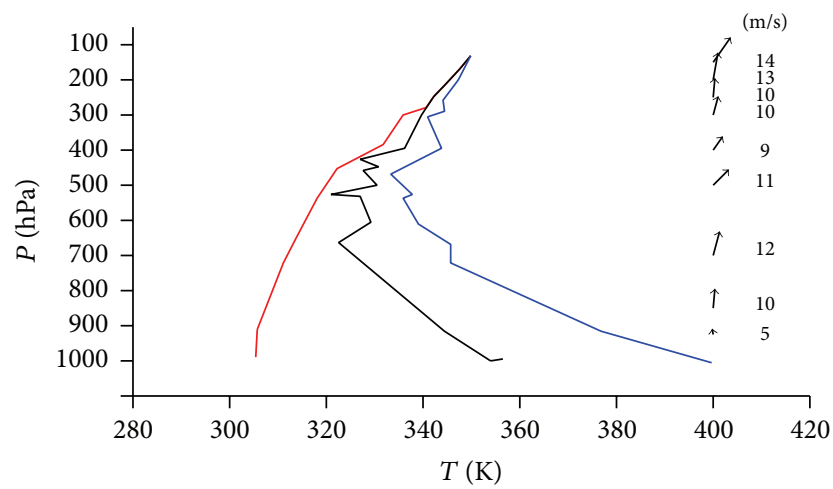

Station: WUHN

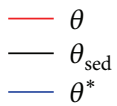

(c)

(d)

Figure 7: $V$-3 $\theta$ distribution conditions: (a) 8:00 a.m. on July 27, 2007, at the YICH station; (b) 8:00 p.m. on July 27, 2007, at the YICH station; (c) 8:00 a.m. on July 27, 2007, at the WUHN station; (d) 8 p.m. on July 27, 2007, at the WUHN station. The red lines are the $\theta$ curves, the green lines are the $\theta_{\text {sed }}$ curves, and the blue lines are the $\theta^{*}$ curves.

reflections were still around $50 \mathrm{dBZ}$. By 8:38 p.m., the storm had moved farther north and the maximum height of the strongest reflections had decreased slightly. The height of the center of the reflections had started to decrease as well, and moreover the reflections had started to weaken.

A vertical analysis of velocity information can give a better picture of the development and evolution characteristics of strong winds at the core of a storm. This is very useful for forecasting thunderstorms. Figure 9 shows a vertical crosssection of the strong radial winds measured with WUHN Station's Doppler weather radar at the same three times shown in Figure 8. This figure shows the existence of a strong wind core at low levels around the time of the storm [26]. At 8:14 p.m., this strong wind core was located $2 \mathrm{~km}$ above the ground and was moving north with the storm. At 8:26 p.m., the strong wind core had lowered to $1 \mathrm{~km}$ above the ground. By
8:38 p.m., the strong wind core was scattered by the ground. This marked the beginning of strong winds at the surface.

Doppler radar is one of the most effective tools for monitoring severe convective weather. By analyzing the special characteristics of the Doppler weather radar products from this storm, especially the Doppler velocity field, we can see that thunderstorms were a kind of strong convective motion. The basic reflectivity of thunderstorms reached around $50 \mathrm{dBZ}$, and they had clear Doppler radial velocity characteristics. They also had very strong core winds that were concentrated in a small region. The core wind region moved closer and closer to the ground as the storm developed. Strong thunderstorm winds occurred at the surface when the core wind section reached the ground level. By using Doppler wind velocity analyses, strong thunderstorm wind warnings can be issued 10-20 minutes in advance. 


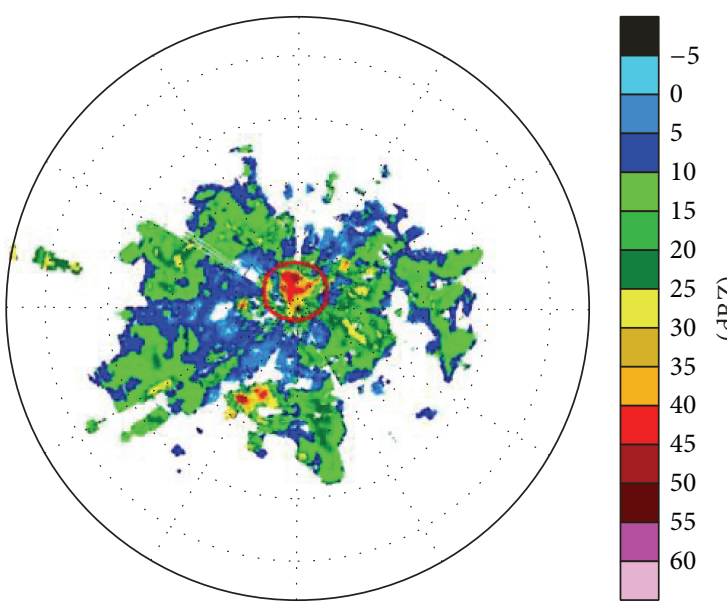

(a)

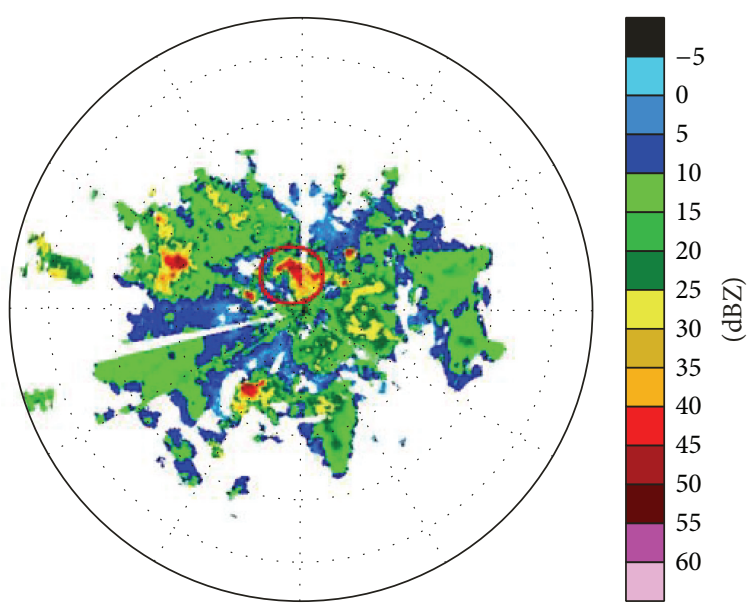

(b)

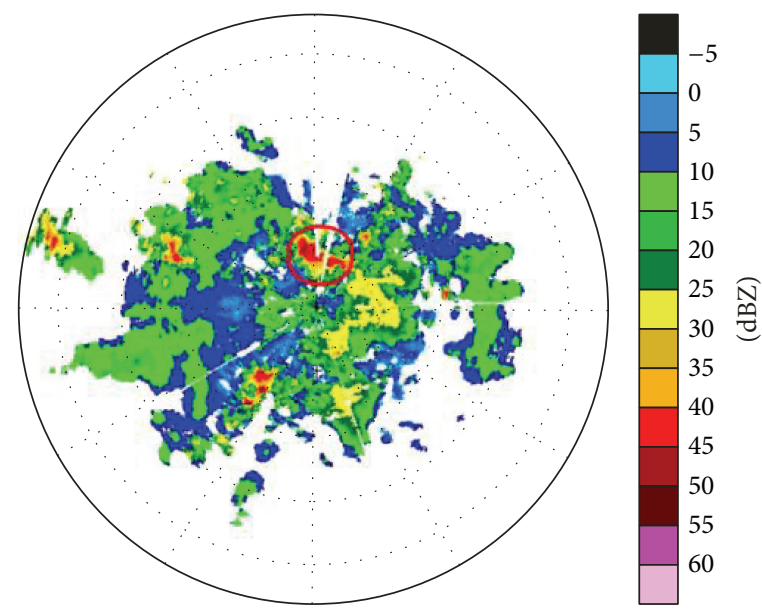

(c)

FIGURE 8: WUHN station Doppler radar basic reflectivity (inclination: $0.5^{\circ}$; range: $230 \mathrm{~km}$ ). Data were collected at the following times (Beijing times): 8:14 p.m. (a); 8:26 p.m. (b); 8:38 p.m. (c).

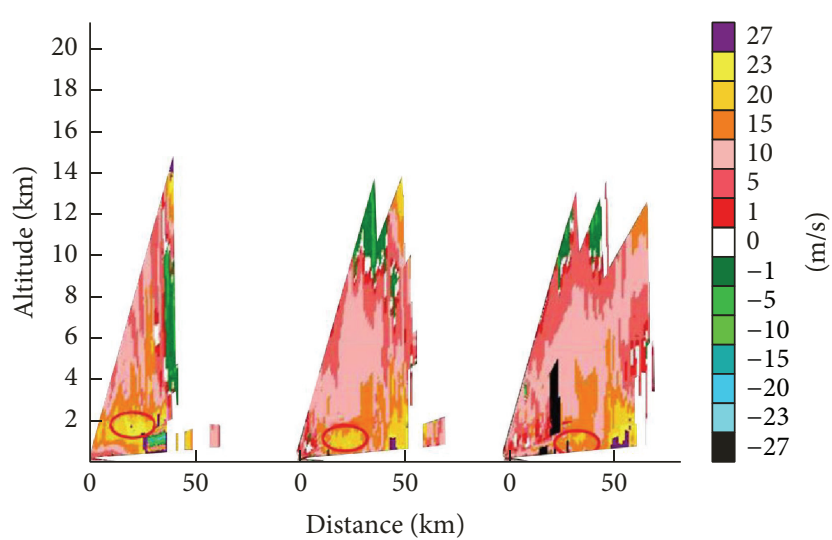

FIGURE 9: Vertical cross sections of radial wind speed as seen by Doppler radar at the WUHN station on July 27, 2007, at 8:14 p.m., azimuth at $342.00^{\circ}$ (left), 8:26 p.m., azimuth at $345.00^{\circ}$ (center), and $8: 38$ p.m., azimuth at $352.00^{\circ}$ (right). The units for the radial wind speed are $\mathrm{m} / \mathrm{s}$.

\section{Conclusions}

This study examined a classic extreme convective weather event that occurred in the Hubei-Hunan region on July 27, 2007. The event consisted of thunderstorms, hail, and strong winds, and the storm caused extensive damage. The primary characteristics of the severe convective weather were revealed by using the wind vector and potential temperature analysis method, and the physical mechanisms of the development of the strong convective weather were explained. The main purpose of this study was to introduce our research findings for severe convective weather events and to supply solutions for problems associated with current forecasting methods. Here, we proposed the use of radar analysis as the primary tool for conducting quantitative analyses and showed that it can improve the accuracy of mechanistic approaches for forecasting strong convective weather in terms of both quantitative and qualitative computations. Although the present study only presented one example, this example included 
strong wind, hail, and thunderstorms, which are typical characteristics of severe convective weather. We believe that these findings can improve the forecasting times for local, strong convective weather events. The overall conclusions were as follows.

(1) The most important characteristic of strong convective weather is the uneven distribution of thermal energy. The structure of this unstable thermal energy distribution determines the level of instability in the atmosphere. In " $V-3 \theta$ " plots, the size of the angles that the $\theta_{\text {sed }}$ and $\theta^{*}$ temperature values make with the $T$ axis reflects the level of instability; that is, larger angles are indicative of more instability. The location of the highest obtuse angle is also important. The higher upon the plot an obtuse angle is formed, the stronger the convective process is.

(2) Another key characteristic of strong convective weather is a rapid drop in temperature at the top of the troposphere preceding the storm process. In this paper, it was referred to as an "ultra-low temperature phenomenon." The appearance of such a phenomenon indicates that the temperature difference between the surface and the top of the troposphere has increased. The larger the temperature gradient between high and low levels of the troposphere, the more intense the convective weather.

(3) In addition to the appearance of an ultra-low temperature phenomenon before strong convective weather occurs, instability emerges in the atmosphere. The entire troposphere will demonstrate a "clockwise rolling current" structure. After severe convective weather begins, unstable energy and moisture are released in huge quantities and the ultra-low temperature layer gradually dissipates.

(4) On the basis of atmospheric data sent from radiosonde probes, it is currently possible to estimate the type and approximate scale of convective weather events that are likely to occur. Radar observations can then be used to refine the location of precipitation zones. Furthermore, the evolution of the strength, location, and height of radar echoes can provide information about the location of the system.

Severe local convective weather events often cause excessive damage because of their rapid development and small size, which makes them difficult to forecast in a timely manner. Currently, observation systems have low resolution and radar monitoring can only provide a few hours or minutes of advanced warning. However, by using comprehensive research on the cumulative process by which each of several classical characteristic quantities changes during the development of strong convective weather systems, we propose that it is possible to detect signals that a storm is brewing. If the overall structure of the components constitutes a physical mechanism (equivalent to a small or medium sized system with a life span of 6 hours), then a credible warning can be issued 6-24 hours in advance of a storm. However, weather station equipment is presently spread out over large distances with temporal and spatial resolutions of 12 hours and $200-300 \mathrm{~km}^{2}$, respectively. Therefore, small-scale $(100 \mathrm{~km}$ or smaller) or short-lived (6 hours or less) weather systems are easily missed by existing radiosonde probe infrastructure. However, ultra-low temperature phenomena, which precede severe convective weather, can consist of a mesoscale or intermediate-scale structure covering $500-1000 \mathrm{~km}^{2}$. Therefore, $V-3 \theta$ plots can be used to identify these ultra-low temperature phenomena. Without them, severe convective weather cannot occur $[2,22,23,25]$. Surely, improving the temporal and spatial resolution of radiosonde information by increasing station density and measurement frequency would improve forecasting capabilities. Here, we suggest that improvements could also be made by using existing infrastructure and applying $V-3 \theta$ information to distinguish conditions that could potentially lead to damaging weather events. The analysis should be qualitative at first. Additional comprehensive analysis of the overall development could be carried out as needed by using other observation equipment and methods. The physical mechanisms that generate ultra-low temperature phenomena should be further studied. Ultra-low temperature phenomena can cause extremely uneven vertical structures in the atmosphere that stimulate and invigorate many types of severe convective weather. A deeper examination of the role that these phenomena play in the evolution of atmospheric processes is left for future study.

\section{Competing Interests}

The authors declare no competing interests.

\section{Authors' Contributions}

Hao Wang conceived this research and designed the study. The paper was written by Hao Wang with significant contributions from Gangyi Chen, Huanhuan Lei, and Yongqian Wang. Shunxian Tang formulated some conclusions.

\section{Acknowledgments}

This work was supported by the National Natural Science Foundation of China (no. 41405036, no. 41471305, and no. 41375043), the 2015 Middle-Aged Academic Leaders Research Fund of Chengdu University of Information Technology (CUIT) (J201502), a Project of the Sichuan Education Office (15ZB0181), the 2015 Open Project of Humanities and Social Science in universities at Sichuan Province (ZHYJ15ZD01), and the Scientific Research Foundation of CUIT (KYTZ201413, CRF201401). The authors also thank Professor Ouyang Shoucheng and the reviewers for their constructive comments and editorial suggestions that significantly improved the quality of the paper. 


\section{References}

[1] H. Wang, J. He, M. Wei, and Z. Zhang, "Synthesis analysis of one severe convection precipitation event in Jiangsu using groundbased GPS technology," Atmosphere, vol. 6, no. 7, pp. 908-927, 2015.

[2] S. Ouyang, Weather Evolution and Structure Prediction, China Meteorological Press, Beijing, China, 1998.

[3] A. K. Showalter, "A stability index for thunderstorm forecasting," Bulletin of the American Meteorological Society, vol. 34, pp. 250-252, 1953.

[4] M. L. Weisman and J. B. Klemp, “The dependence of numerically simulated convective storms on vertical wind shear and buoyancy," Monthly Weather Review, vol. 110, no. 6, pp. 504-520, 1982.

[5] J. A. Hart and W. D. Korotky, The SHARP Workstation-V1.50. A Skew T/Hodograph Analysis and Research Program for the IBM and Compatible PC. User's Manual, NOAA/NWS Forecast Office, Charleston, WVa, USA, 1991.

[6] C. A. Doswell III and E. N. Rasmussen, "The effect of neglecting the virtual temperature correction on CAPE calculations," Weather and Forecasting, vol. 9, no. 4, pp. 625-629, 1994.

[7] E. N. Rasmussen and D. O. Blanchard, "A baseline climatology of sounding-derived supercell and tornado forecast parameters," Weather and Forecasting, vol. 13, no. 4, pp. 1148-1164, 1998.

[8] D. O. Blanchard, "Assessing the vertical distribution of convective available potential energy," Weather and Forecasting, vol. 13, no. 3, pp. 870-877, 1998.

[9] L. Gao, Theoretical Studies and Diagnostic Analyses of Perturbation Potential Energy, Graduate School of the Chinese Academy of Sciences, Beijing, China, 2006.

[10] X. Yu, X. Zhou, and X. Wang, "The advances in the nowcasting techniques on thunderstorms and severe convection," Acta Meteorologica Sinica, vol. 70, no. 3, pp. 311-337, 2012.

[11] M. Xue, M. Hu, and A. D. Schenkman, "Numerical prediction of the 8 May 2003 Oklahoma city tornadic supercell and embedded tornado using ARPS with the assimilation of WSR88D data," Weather and Forecasting, vol. 29, no. 1, pp. 39-62, 2014.

[12] B. Xi, X. Yu, and L. Sun, "Generating mechanism and type of gust front and its subjective identification methods," Meteorological Monthly, vol. 41, no. 2, pp. 133-142, 2015.

[13] H. Wang, M. Wei, G. Li, S. Zhou, and Q. Zeng, "Analysis of precipitable water vapor from GPS measurements in Chengdu region: distribution and evolution characteristics in autumn," Advances in Space Research, vol. 52, no. 4, pp. 656-667, 2013.

[14] A. Marinaki, M. Spiliotopoulos, and H. Michalopoulou, "Evaluation-of atmospheric instability indices in Greece," Advances in Geosciences, vol. 7, pp. 131-135, 2006.

[15] W. Lin, C. Lin, B. Chen, and Y. Yu, "Atmospheric vertical structure charateristics of hail weathers in northwest Fujian," Journal of Natural Disasters, vol. 23, no. 4, pp. 212-218, 2014.

[16] J. Jiang, X. Zhang, M. Wei, and L. Shi, "Application of V-30 chart in forecasting of a severe storm," Meteorological Science and Technology, vol. 40, no. 4, pp. 647-650, 2012.

[17] M. Wei and S. Ouyang, "On subtropical anticyclone and high temperature drought in relation to the earth nutation and rotation," Engineering Sciences, vol. 9, no. 8, pp. 40-46, 2007.

[18] M. Wei and S. Ouyang, "Characteristics of atmospheric structure and earth rotation of drought from winter in 2008 to spring in 2009," Engineering Sciences, vol. 13, no. 1, pp. 49-55, 2008.
[19] H.-Z. Chen, "Structure analysis of irregular information and regional fog forecast," Journal of Natural Disasters, vol. 14, no. 5, pp. 43-48, 2005.

[20] L. Zhong, Z. Zhang, L. Chen, J. Yang, and F. Zou, "Application of the Doppler weather radar in real-time quality control of hourly gauge precipitation in eastern China," Atmospheric Research, vol. 172-173, pp. 109-118, 2016.

[21] D. Bolton, "The computation of equivalent potential temperature," Monthly Weather Review, vol. 108, no. 7, pp. 1046-1053, 1980.

[22] Y. Lin and S. Ouyang, Irregularities and Prediction of Major Disasters, CRC Press, Boca Raton, Fla, USA, 2010.

[23] S. Ouyang, G. Chen, and Y. Lin, Information Digitalization and Forecasting, China Meteorological Press, Beijing, China, 2009.

[24] J. Wallace and P. Hobbs, Atmospheric Science: An Introductory Survey, Academic Press, New York, NY, USA, 2nd edition, 2006.

[25] L. Peng, T. Xiao, and C. Li, "Application of ultra-low temperature structure to long-term prediction," Journal of Chengdu University of Information Technology, vol. 17, no. 1, pp. 14-19, 2002.

[26] J. Wang, J. Zhang, Y. Wang, and Y. Mao, "Characters of Doppler radar velocity on intense gust in the east of Hubei Province," Torrential Rain and Disasters, vol. 28, no. 2, pp. 143-146, 2009. 

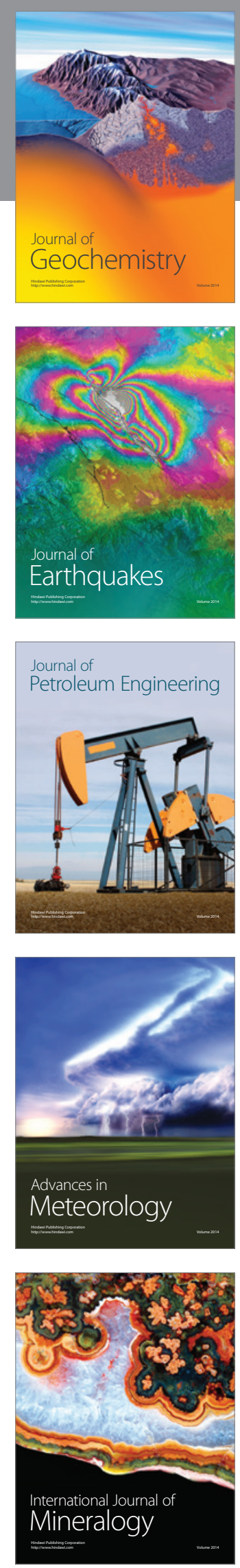
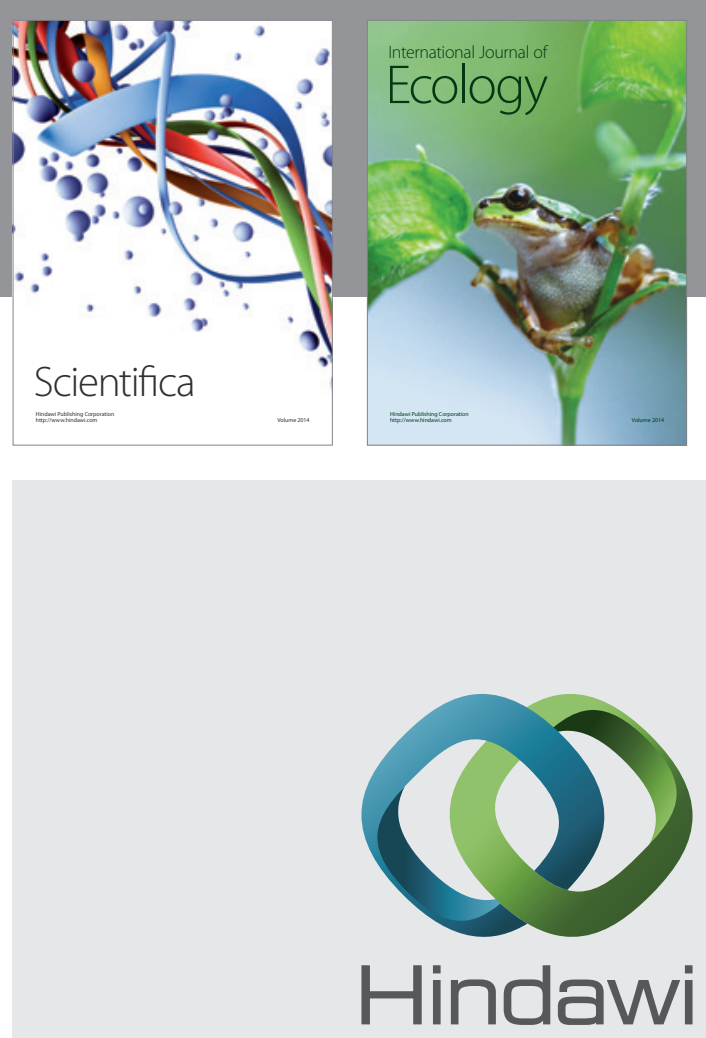

Submit your manuscripts at

http://www.hindawi.com
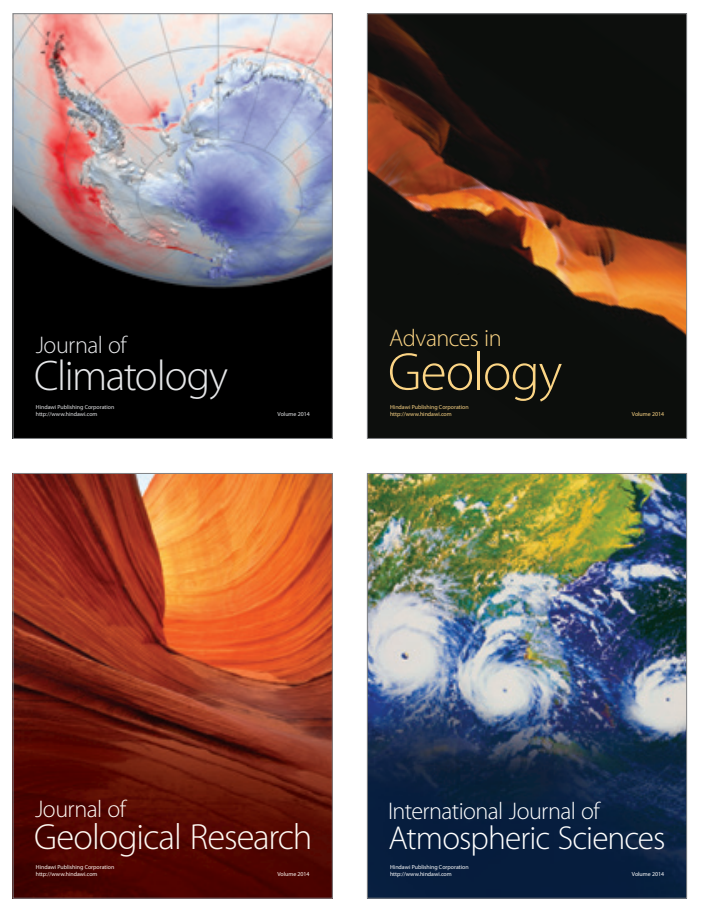

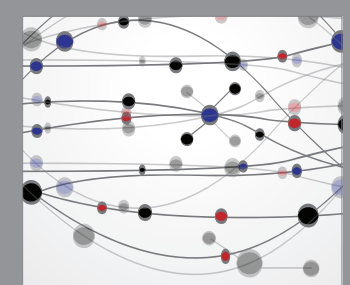

The Scientific

\section{World Journal}
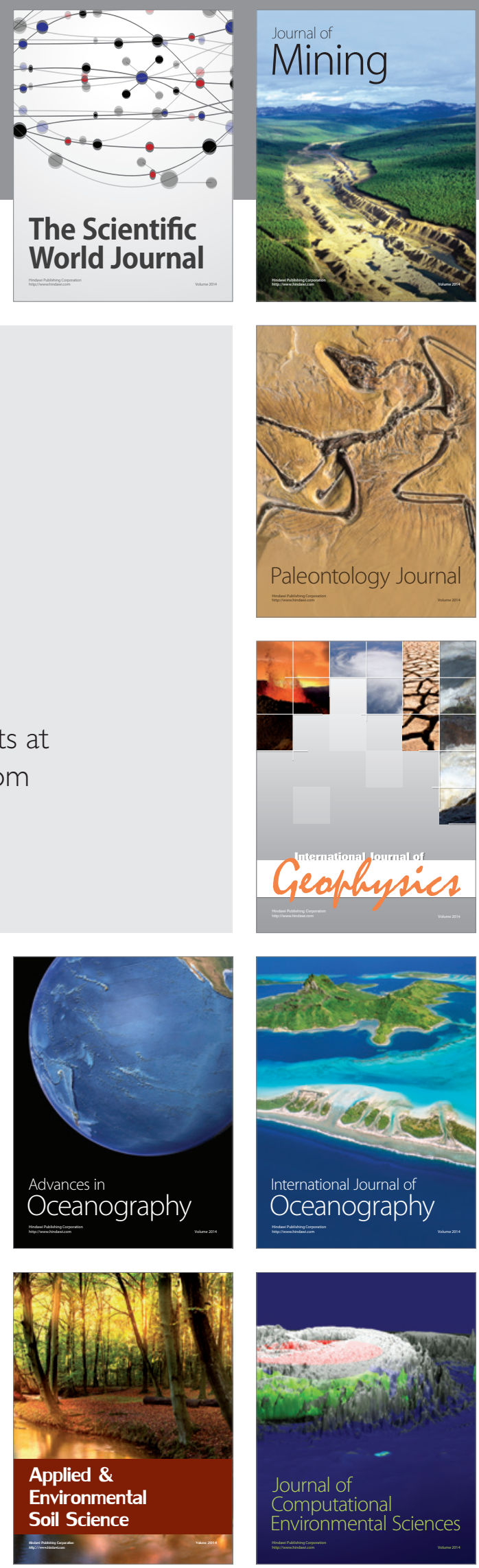